\title{
Value orientation, left-right placement and voting
}

\author{
JAN W. VAN DETH \& PETER A.T.M. GEURTS \\ University of Twente, The Netherlands
}

\begin{abstract}
In this article we try to disentangle the constraints between traditional lines of political polarization (left-right placement) and newer distinctions (materialist/postmaterialist values) among mass publics. It is shown that voting or party preference is most clearly related to the left-right placement of the respondents. However, this placement is directly and strongly dependent on the materialist/postmaterialist orientation, while background variables like education, income and age are linked to voting via this value orientation. The materialist/postmaterialist orientation appears to be the present-day interpretation of the dominant political conflict in advanced industrial society. Although alignments and orientations count for a substantive part of the variance in voting, the power of these models to predict the actual vote of people turns out to be rather poor.
\end{abstract}

Especially in Western European countries, political ideas and perceptions have been summarized for decades with the use of positions on a single left-right dimension. Usually, this dimension is considered to reflect some general stand on questions concerning the socio-economic structure of society. A more left position means that one favours 'social change in the direction of greater equality', ${ }^{1}$ while a location on the right side represents opposition to such changes. Political cleavages are expressed by associating the terms left and right with proletarian and bourgeois interests respectively. Although the process of 'de-alignment' seems to have eroded these linkages, the left-right dimension is still considered the most important generalized orientation frame for politics in many countries. ${ }^{2}$

In search of the explanation of recent social and political developments in advanced industrial societies, many authors noticed the limitations of the traditional left-right scheme. In addition, a change in value orientations was assumed to deal with more actual political cleavages. According to this view, the wave of political activism in the 1960s, the rise of the feminist movement, the concern for the environment and disarmament, and eventually the foundation of Green parties in several countries, are all the result of a shift in the political priorities among people. Instead of docility, material advantages, and traditions, the post-war generations in particular tend to emphasize selffulfilment, independence and emancipation. Consequently, the traditional, class-related political cleavages among the population gradually lose their 
relevance and new conflict dimensions arise. One of the most fruitful conceptualizations of this new dimension seems to be Inglehart's idea of the contrast between materialist and postmaterialist value orientations. ${ }^{3}$

The interpretation of social and political change in terms of arising new conflict dimensions does not imply a rejection of the use of the left-right dimension. On the contrary. The advantage of introducing the idea of new cleavages is that they overlap, or at least complement, the old cleavages, and so add to our understanding of the dynamics of political change. The main problem to be discussed here is whether or not it makes sense to use the materialist/postmaterialist value orientation in addition to the left-right placement in explanations and predictions of party preferences or voting.

\section{Cleavages and party preferences}

The impact of the left-right placement and the materialist/postmaterialist value orientation on the party preferences or voting of people can be conceptualized in several ways. Many of the logical possibilities in this field have been put forward by Inglehart, his allies, or his opponents. ${ }^{4}$

A first way to interprete these linkages is to present the value orientations as an alternative to the left-right placement. As a result of the gradual disappearance of class-related conflicts in advanced industrial societies, the corresponding political expression in terms of the left-right dimension loses its relevance. New conflict dimensions will replace the old one, and more and more people will base their party preference on their interpretation of new cleavages. In other words, the decline of industrial society means the decline of the relevance of the left-right continuum as a way of expressing class-related conflicts.

The idea of a gradual shift from old to new cleavages does not seem to be very realistic. Instead of presenting a new cleavage as an alternative, it is put forward as a complement of the left-right dimension. In this view, the left-right continuum remains the predominant frame of reference, but now the materialist/postmaterialist value orientation is presented as a new dimension within the left (cf. Kaase and Klingemann 1982). People on the left side agree on the importance of socio-economic change in an egalitarian direction, but they disagree on the priority of materialist and postmaterialist values. So, adding the idea of new cleavages means that the conflict between the 'old left' and the 'new left' is incorporated in the analyses of party preferences and voting.

The third way to link left-right placement and value orientations is to see the latter as an interpretation of the former. Since the majority of people in every country show materialist or mixed orientations, postmaterialists have to plead for changes in order to realize their political goals. A positive attitude towards social change is associated with leftist political stands. Consequently, postma- 
terialists will be on the left side of the left-right dimension and prefer left parties (cf. Inglehart 1979: 335; Inglehart and Rabier 1986: 474; Van Deth 1984: 190-191). In this view, it is the readiness to change of the left, irrespective of the socio-economic interpretation of these changes, that attracts people with a postmaterialist value orientation. The interesting point here is that this interpretation contradicts the notion that party preference basically is a result of class position. As a new middle class, postmaterialists should favour parties from the centre or the right side. However, their need to support political change urges them to prefer left parties. So, the introduction of new cleavages leads to quite different predictions about the party preference of, especially, the postmaterialists than can be obtained on the basis of the old cleavages only.

The fourth and last explanation of voting or party preferences to be mentioned here, is the rejection of the idea that the materialist/postmaterialist value orientation contributes anything substantial or substantive once the left-right placement is taken into consideration (cf. Van der Eijk and Niemöller 1986, 1987). According to this line of reasoning, the left-right dimension still represents the most important ideological cleavage among the populations of advanced industrial societies. That is not to say that supporters of this interpretation stick to some old-fashioned class-related interpretation of the left-right dimension, or that they deny the relevance of the materialist/postmaterialist value orientation in the analyses of political change. The point is that those new cleavages are not (yet?) transformed into party preferences or perceptions of the parties, while there are no reasons to expect a decline of the usefulness of the left-right dimension in this field. This latter dimension functions as generalized frame of reference for political or ideological thinking. Its precise contextual meaning differs from time to time and from place to place.

These four divergent views represent the broad lines of available interpretations of the relationships between values, left-right placements and party preferences. There are, to be sure, other ways of linking these three concepts. If we leave aside the possibility that party preference or voting can be a cause instead of an effect of the left-right placement and/or the materialist/postmaterialist value orientation, then this set of four interpretations seems to be a reasonable start for a more detailed, empirically based analysis.

\section{Operationalization and measurement}

An empirical analysis of the relative impacts of the left-right placement and the materialist/postmaterialist value orientation on party preferences, requires independent measures for each of these three concepts. Usually, left-right placement is registered by presenting a self-anchoring scale formed by ten 
horizontally placed boxes. The terms 'left' and 'right' are placed at the left and right side respectively. Without giving the respondents any further information, they are asked to mark their own position on the dimension.

The materialist/postmaterialist value orientation is measured in a much more complex way. In the most simple variant of the procedure, people are asked to rank four cards according to their own preferences. Each card contains a political goal. Those respondents who give top priority to the postmaterialist statements are labeled 'postmaterialists'; if materialist items are selected first, people are called 'materialists'. Respondents placing both materialist and postmaterialist items among their first few choices, are labeled 'mixed'. Several variants of this instrument have been used with 4,8 or 12 items. ${ }^{5}$

Party preference or voting is measured in straightforward ways: people are simply asked to mention the party they prefer or recently voted for, or the party they would vote for if there were general elections tomorrow. While these registrations seem to be rather harmless and uncomplicated, severe conceptual and methodological problems are encountered when we try to link the left-right placement and the materialist/postmaterialist orientation to party preference or voting.

In order to apply sophisticated multivariate analysis techniques to test the interpretations presented in the previous section, an order or a ranking of the parties is required. For the left-right placement of parties two methods have been tried. Some authors simply rely on expertise or folk wisdom to place the political parties on a dimension (cf. Castles and Mair 1984). The risks involved in terms of reliability, contamination, and verification are obvious, and this method does not seem to be useful for the analyses required here. A substantial improvement can be obtained by asking the respondents to place each party on a left-right dimension. By using the average position of a party on that dimension, we have a second way to identify parties on a left-right dimension. ${ }^{6}$ However, it is hard to imagine how this method can be used in the case of the materialist/postmaterialist value orientation. Van der Eijk and Niemöller (1986) solved this problem by classifying parties according to the relative number of voters with materialist or postmaterialist orientations for each party. We will return to this suggestion below. For the moment, the main conclusion is that there are no more or less equivalent measures available for party preference or voting in terms of the left-right dimension and the materialist/postmaterialist value orientation.

Apart from these operational complications, defining party preference or voting as a dependent variable presents some other, perhaps even more serious, complications. Suppose that we find a useful way to place the parties on a left-right dimension. It will be hardly surprising to find, in an empirical analysis of party preference, that people who call themselves 'right' prefer parties on the right, or people on the left preferring leftist parties. Does that 
result mean that the materialist/postmaterialist value orientation is irrelevant for party preferences? Obviously not. A hypothetical order or ranking of parties along some materialist/postmaterialist dimension probably would lead to the conclusion that postmaterialists have a greater tendency to vote for postmaterialist parties than materialists have. As Prewitt and Nie put it so nicely: 'We would not be surprised to learn that persons who call themselves Catholic are more likely to be found on Sunday in Catholic than in Protestant churches' (1971: 487). The question, then, is how to obtain an order or ranking of the parties without introducing a clear bias for either the left-right placement or the materialist/postmaterialist orientation from the beginning?

\section{Characterizing parties}

Using several characteristics to typify political parties as a dependent variable only makes sense if the number of parties allows for at least some differentiation. The Dutch multi-party system is among the few political systems in the world that incorporate a magnitude of parties differing in many respects. Furthermore, the pure postmaterialists constitute a substantial minority in the Netherlands while this orientation is less clearly present in other countries. These two reasons seems to designate the Dutch political system as an excellent location to test the expectations on the relative impact of left-right placement and materialist/postmaterialist value orientation on party preferences or voting.?

Van der Eijk and Niemöller (1986: 266, 269) used the relative number of postmaterialists among the voters for a particular party in the Netherlands as the criterion to rank that party on a 'postmaterialist dimension'. This relative number of postmaterialists is the average percentage of postmaterialists for that party in six large-scale surveys (Eurobarometer 13 up to Eurobarometer 18). In a similar way, the parties are ranked on a 'materialist dimension'. Van der Eijk and Niemöller used these two scales in their analysis of the impact of left-right placement and materialist/postmaterialist orientation in the Dutch Parliamentary Election Study of $1981 .{ }^{8}$ In fact, they performed three separate analyses with the left-right placement and value orientation as the main independent variables, and reported voting behaviour scored according to 1) the mean placement of the party voted for on a left-right scale, or 2) the mean percentage of postmaterialists among the voters for that party, or 3) the mean percentage of materialists. Their conclusion simply is that the materialist/ postmaterialist orientation is not a new electoral dimension: ' . . postmaterialism is shown to be dependent on ideological left-right orientations rather than being an independent and rivaling influence on political choice' (Van der Eijk and Niemöller 1986: 251). Instead of discussing all the pitfalls encountered by 
the analyses presented by Van der Eijk and Niemöller, we will show that a more balanced and unbiased way to deal with the dependent variable leads to quite different conclusions.

A fair test of the impact of left-right placement and value orientation on voting requires that each party is characterized according to these cleavages. For that purpose, we pooled the available surveys of the same type held in the Netherlands in the period from 1976 through 1981. These data collections should have identical measures for left-right placement, value orientation and voting or party preference. It appeared that Eurobarometers 6 through Eurobarometer 16 satisfy these criteria. ${ }^{9} \mathrm{With}$ this pooled data set, for each party the relative number of postmaterialists and materialists is computed among the voters for that party. The left-right placement was treated in a similar way by computing the relative number of people with a left stand (scores 1,2 or 3 ) and the relative number of people with a right stand (scores 8,9 or 10). The result is that each party is typified with four characteristics: the percentages leftists, rightists, postmaterialists, and materialists among its potential voters in the period before the national election of $1981 .{ }^{10}$ The figures obtained for the main Dutch parties in the period under consideration are presented in Table 1. We will not summarize these four characteristics in a single measure, but include their relationships in our empirical analyses.

It should be stressed, moreover, that no use is made here of any perceptions of the parties apart from the vote intention reported by the respondents. Furthermore, the two rival independent variables are treated in the same way as much as possible. The objection can be raised that this procedure does not reduce the risks of contamination but, on the contrary, doubles the number of

Table 1. Characteristics of Dutch political parties.

\begin{tabular}{|c|c|c|c|c|c|c|}
\hline \multirow[t]{2}{*}{ Party: } & \multicolumn{3}{|c|}{ left-right placement } & \multicolumn{3}{|c|}{ value orientation } \\
\hline & $\%$ left & $\%$ right & $(n)$ & $\%$ post & $\%$ mat & $(\mathrm{n})$ \\
\hline PvdA & 51 & 5 & 2669 & 21 & 30 & 2687 \\
\hline CDA & 3 & 44 & 2646 & 9 & 39 & 2664 \\
\hline VVD & 3 & 43 & 1335 & 10 & 34 & 1325 \\
\hline D66 & 20 & 5 & 970 & 26 & 23 & 967 \\
\hline CPN & 73 & 1 & 90 & 29 & 19 & 90 \\
\hline PPR $^{*}$ & 64 & 2 & 225 & 57 & 5 & 221 \\
\hline PSP* & 78 & 2 & 218 & 65 & 5 & 220 \\
\hline DS70 & 9 & 9 & 55 & 17 & 31 & 52 \\
\hline SGP & 3 & 79 & 121 & 3 & 49 & 115 \\
\hline GPV & 1 & 68 & 78 & 5 & 44 & 86 \\
\hline
\end{tabular}

* the scores for PPR and PSP are merged in Eurobarometer 6 . For that survey we attributed the votes for this combination of parties to each of the parties separately. 
contaminated variables. Although this remark certainly makes sense in analyses of voting and party preferences, we decided to apply the procedure for several reasons. First, the risks of contamination are lowered for both factors by not using perceptions of respondents to characterize the parties. Second, the main objective here is to disentangle the relative impacts of left-right placement and value orientation. If there is a risk of contamination, then this risk should be equally distributed among the predictor variables. Third, the parties are characterized by using data sets (the Eurobarometers) that are clearly distinct from the data we use for the analysis of voting (the Parliamentary Election Study of 1981). Fourth, the operationalization of voting as proposed is different but comparable to the operationalizations used by other researchers. Therefore, our results can be directly contrasted to conclusions to be found in the literature on the relevance of the materialist/postmaterialist orientation. As will be illustrated below, quite different results are obtained in empirical analyses when left-right placement and value orientation are treated in the same way as much as possible.

\section{Explaining voting}

As a first step towards assessing the empirical constraints among left-right placement, value orientation and voting, a simple model with voting as the dependent variable and the two other concepts as the independent variables will be constructed. As mentioned earlier, in the Dutch Parliamentary Election Study 1981 voting is operationalized as the reported voting behaviour in that election, and the party preferred is typified by four characteristics. For the left-right placement, the usual ten-points scale is used, while the materialist/ postmaterialist value orientation is measured with a three-points typology based on the factor scores on twelve items. ${ }^{11}$

The relative impact of the two independent variables on voting can be estimated with a set of simultaneous equations. Actually, we used the LISREL algorithms to compute these estimates. ${ }^{12}$ Structural relationships are considered to exist from left-right placement and value orientation on voting, and between the first two variables. The measurement model for voting consists of the four characteristics of the parties mentioned in the previous section. We tried to fit several variants of this model with the data. The variants with the best estimates, from a statistical point of view, are presented in Fig. 1.

The best fitting models are the ones with value orientation as the alternative for the left-right placement and, with almost exactly the same statistical results, the model we introduced under the name interpretation, i.e. the left-right placement as intermediating factor between value orientation and voting. The explained variance for both models is very high. In the interpreta- 


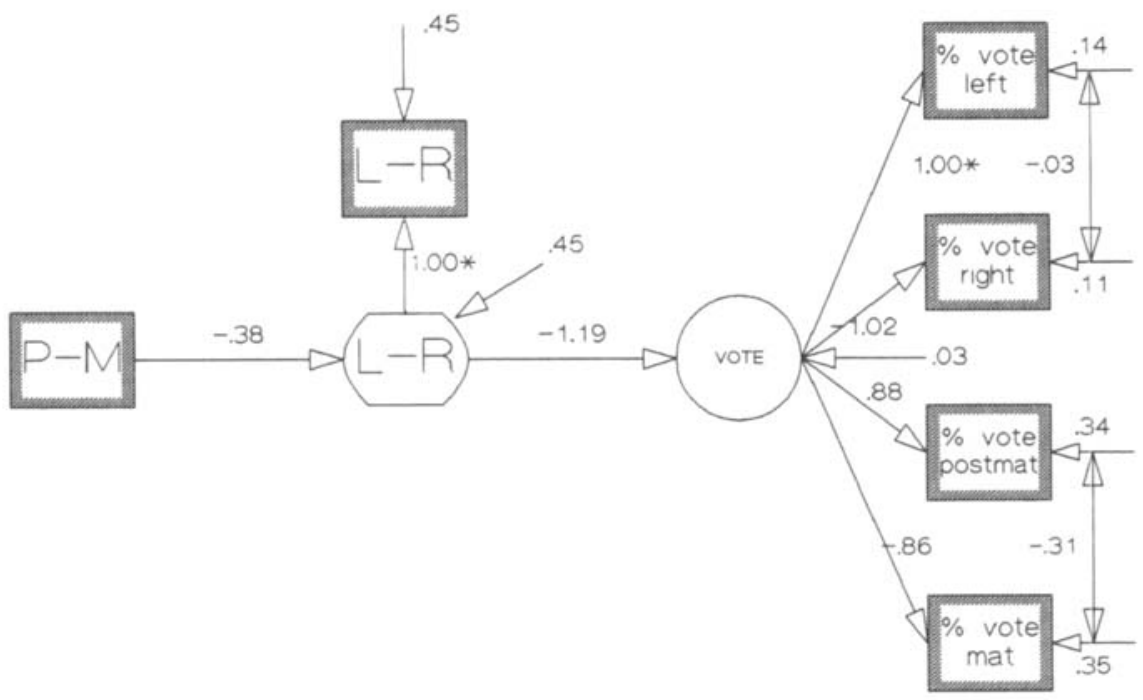

the interpretation model

$\mathrm{R}^{2}{ }_{\text {vote }}=.97 \mathrm{AGFI}=.998$ Variance of 'vote' $=.86 \quad \mathrm{Max}_{\text {residual }}=.0588^{\circ}=$ fixed value

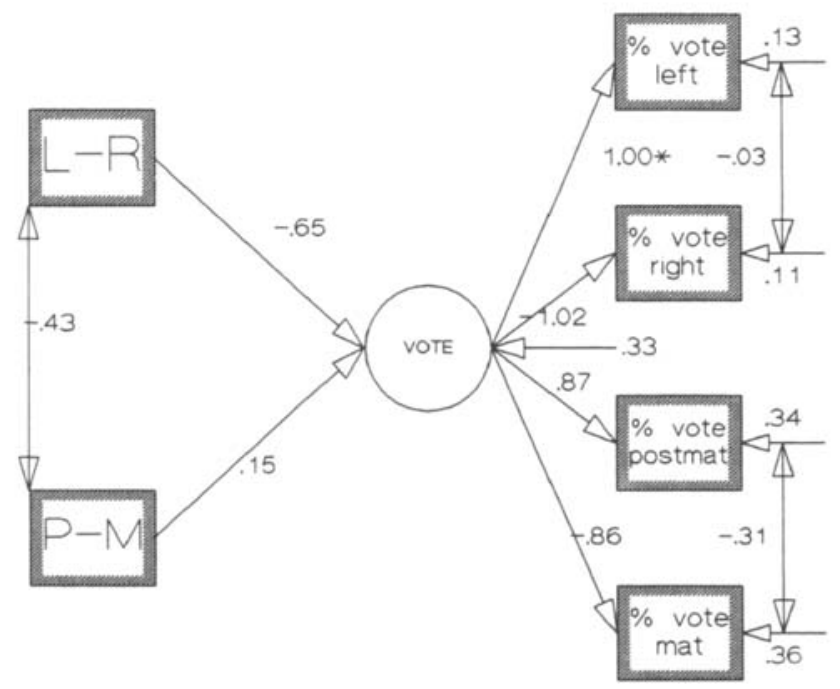

the alternative model

$\mathrm{R}^{2}{ }_{\text {vote }}=.62 \mathrm{AGFI}=.999$ Variance of 'vote' $=.87$ Max $_{\text {residual }}=.043^{\circ}=$ fixed value

Fig. 1. LISREL-estimates of the interpretation and the alternative model. 
tion model the left-right placement and the materialist/postmaterialist orientation explain most of the variance of voting; furthermore, the residuals are all very small. So, the solutions presented in Fig. 1 are to be taken as fitting very well. ${ }^{13}$

A closer look at the two solutions shows that the measurement models in both tests are almost identical. The indicators for the percentages of leftist voters and rightist voters fit somewhat better than the indicators for the percentages of postmaterialist and materialist voters. Because of possible contamination between the first two indicators and the last two, correlations between the residuals are introduced. Since we use the two extreme parts of the properties of the voters of a party, it can be expected that the indicators for each property are contaminated. For instance, a very large portion of materialists for a party places severe limitations on the relative share of postmaterialists. By introducing the possibility of correlated residuals, this aspect is taken into account. As can be seen in Fig. 1 there is indeed some correlation between the residuals. ${ }^{14}$

A possible objection against our analyses so far, could be that there is no need for an elaborated objective and non-contaminated measure of voting, because people vote directly for some left or right party without some general translation of political orientations in a vote intention. A partial indication for the importance of such direct issue voting can be found in the residuals between left-right placement and the indicators of voting. These residuals are all less than .025 (not presented in Fig. 1.) Moreover, the correlations between the residuals do not point in the direction as suggested by the above mentioned critical view. The same holds for the materialist/postmaterialist orientation in relation to the indicators of voting. On this point the conclusion must be that the measurement model is valid for the concept of voting or party preference.

The fit of the two models presented in Fig. 1 is opposite to the results of an empirical test of the other models: the rejection model and the complement model. Typical for both these last models is that there is, in fact, no place for a more general value orientation as measured by the materialist/postmaterialist variable. A test of the most extreme model - a rejection of the relevance of the materialist/postmaterialist variable by explaining voting by left-right placement only - leads to a clear misspecification of the model on the data. ${ }^{15}$ Furthermore, the thesis that postmaterialism should be a tie-breaker between some left parties (a radical version of the complement model) may be tested by a model in which left-right placement is exogeneous and considered to explain voting directly and via the materialist/postmaterialist orientation. In this case, we find a non-positive definite matrix of the residuals of the measurement model: ${ }^{16}$ a clear indication for the misspecification of the model.

The empirical results obtained with the nuclear triangle of left-right placement, value orientation and voting can be seriously influenced by background 
variables. Before we accept a conclusion about the relative impact of left-right placement and value orientation, a more elaborated model has to be considered. In a model like that, the following background variables can be included: generation (indicated by age) as an indicator for the period in which one is socialized; income as an indicator for the degree in which materialist/postmaterialist issues are of direct relevance to the person; education as an indicator for socialization in the bourgeois values of the dominant class; and sex as an indicator for the socialization in specific societal roles. ${ }^{17}$

The best fitting and, at the same time, most elegant solution from a theoretical point of view, is presented in Fig. 2. The overall fit of the model is very good, and the parameters within the nuclear triangle are almost identical to the parameters of the limited models presented in Fig. 1. This suggests that the specific way of measuring voting or party preference is very stable. With the exception for the residuals between education and income on the one hand, and the indicators of voting on the other hand, none of the residuals are larger than .06 .

The most substantial relationships between the background variables and the left-right self placement, and these variables and the materialist/postmaterialist value orientation are presented in Fig. 2. At the same time, these

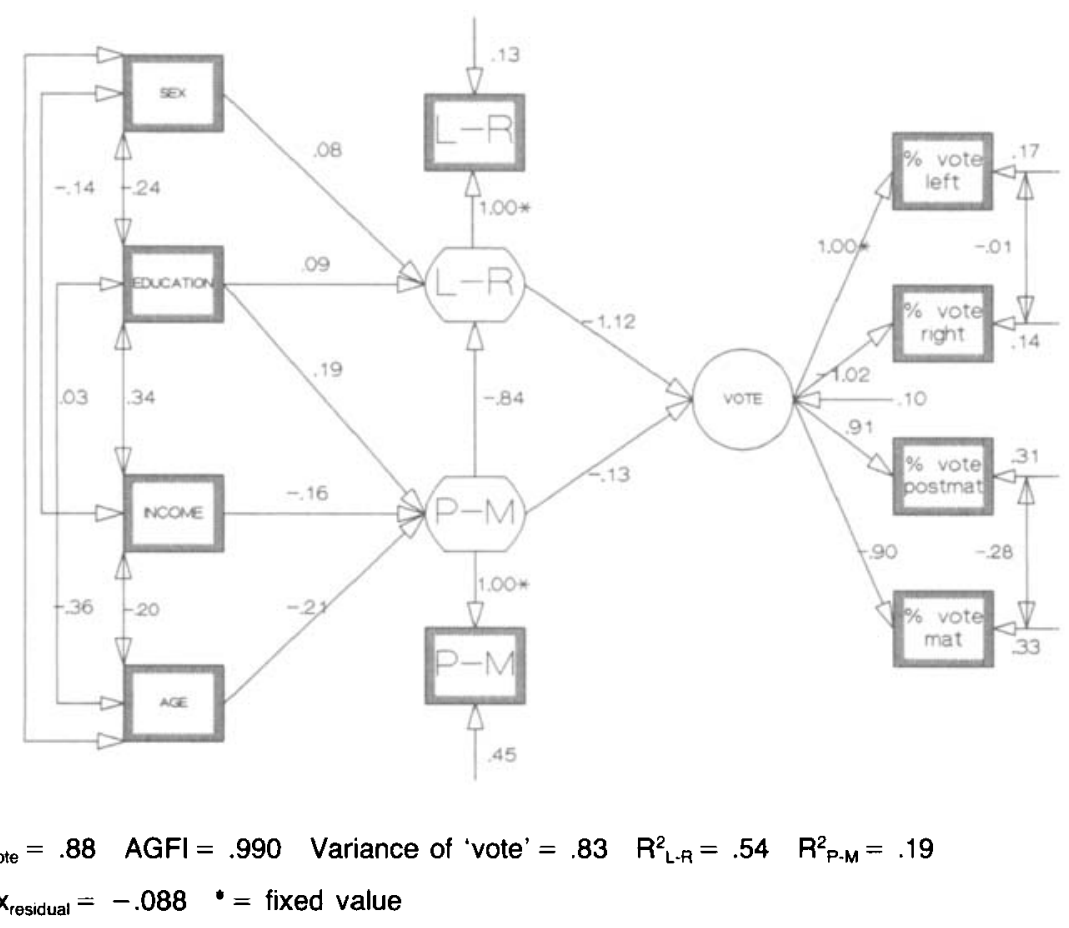

Fig. 2. LISREL-estimates of the elaborated model. 
relationships are all in line with the expectations spelled out in the literature on value change. ${ }^{18}$ Sex is not related with the materialist/postmaterialist value orientation. Education and sex explain very little of left-right placement. As far as the background variables have an impact on the left-right placement, the materialist/postmaterialist orientation is needed as a mediating variable. This is an additional argument for the idea that the materialist/postmaterialist value orientation provides an interpretation of the voting behaviour along the leftright dimension. Consequently, the parameters between the materialist/postmaterialist value orientation and income, education and age are at a considerable level.

The results of these empirical analyses imply much more balanced and subtle conclusions on the relative impacts of left-right placement and value orientation than has been put forward recently. For instance, Van der Eijk and Niemöller's (1987: 17) statement that 'Post-materialist orientations are of negligible importance in a causal model of party choice' is clearly an artefact of their biased treatment of the dependent variables. It should be noted that the present analyses are based on the very same data set as used by Van der Eijk and Niemöller $(1986 ; 1987)$. However, both the theoretical and technical aspects of our work differ at several crucial points. ${ }^{19}$ It will be no surprise that we reject Van der Eijk and Niemöller's (1987: 28) final remark that their work '. . simultaneously undermines the validity of a great number of previous research findings' in the field of materialism/postmaterialism, as unconvincing and premature.

\section{Predicting voting}

So far, attention has been paid to the explanation of voting in terms of left-right placement and value orientation. Although the fit of the models presented in Fig. 1 and Fig. 2 is very satisfying, the statistical properties reported reflect tendencies only in the covariance structures of the data. Since the proof of the pudding is in the eating, the next question to be answered is whether or not the model developed here can be used to predict the actual vote of a substantial number of respondents.

Obviously, the prediction of the actual vote of the respondents cannot be derived from the same data set as the one used for the estimation of the parameters of the model. Because there is no identical data set available we decided to split the sample of the Dutch Parliamentary Election Study 1981 at random in two halves of 810 cases each. The first subsample is used to estimate the parameters of the elaborated model developed in the previous section (see Fig. 2). The second subsample is reserved for the test of the prediction of the 
actual vote. This procedure implies that parameter estimation and prediction of the vote are almost completely uncontaminated.

In order to compare the actual vote with the predicted vote, a scaling of the parties along some dimension is needed. The scaling procedure is part of the measurement model of the first subsample. More precisely, the factor regression coefficients of this subsample can be used to calculate voting behaviour of every repondent in terms of a one-dimensional voting profile of the parties. ${ }^{20}$ Every party vote now has a value on this single dimension. The results are standardized to facilitate a comparison with the predictions to be derived from the second subsample. These predictions are obtained by applying the LISREL-estimates of the first subsample to the relevant variables of the second subsample. In other words, the scores on left-right placement, value orientation, education, income, age, and sex of each respondent in the second subsample are used to compute their scores on the voting profile of the parties by using the parameters of the first subsample. ${ }^{21}$ Again, because the data and parameters originate from distinct subsamples, the results are standardized.

The power of the model developed here to predict actual voting can be assessed in several ways. First, the correlation between the predicted and the actual vote is computed. This coefficient is .64 - a rather disappointing figure. However, the emphasis here is on actual prediction and not on yet another indication of tendencies. The second way to assess the power is to apply a variant of the nearest distance hypothesis of voting behaviour. In this case we assume that the prediction is correct if the predicted vote of a respondent is nearer to the actual vote than to any other party. ${ }^{22}$ Now, the vote of 20.9 percent of our respondents is correctly predicted with the estimates of our model. Leaving aside the very small DS'70 party increases this number to 24.8 percent. These figures are even more disappointing than the correlation coefficient reported above. A third way to assess the power of our model is to weaken the specification of the predicted vote somewhat further. Suppose that the voter selects one of the two parties that demarcate the region his estimated party vote belongs to, irrespective of the distance to these parties. Applying this modified variant of the nearest distance hypothesis results in a correct prediction of 31.5 percent of the respondents. Leaving out the single DS'70voter in the region between PvdA and CDA increases this number to 40.1 percent.

Although these figures indicate that the actual vote of a part of the respondents can be predicted with the model, it should be noted that a substantial proportion of our respondents select a party not in line with the expectations. Furthermore, the power of the model is clearly overestimated by using the percentages of correct votes as an indicator. A total number of ten parties implies that we can expect a correct prediction of the vote for about nine percent of our respondents (combining the missing values on the vote-varia- 
Actual Vote (across) by Predicted Vote (down)

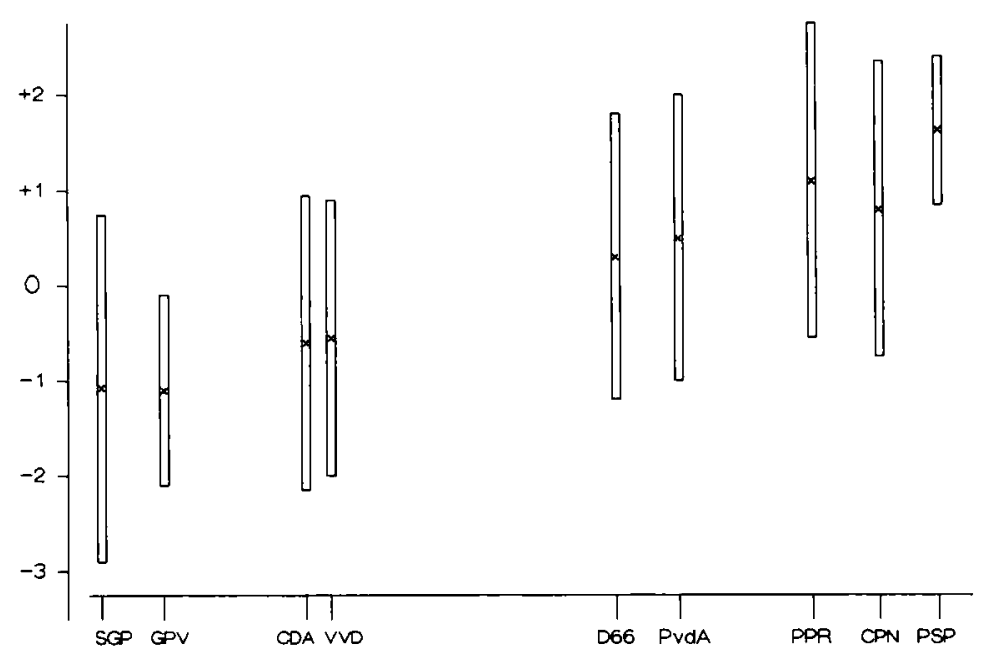

Fig. 3. Actual and predicted votes (means and $95 \%$-confidence intervals).

bleas a separate 'party') by simply assuming random voting. This line of reasoning relies on the assumption that we do not know anything about the differences in size of the parties. However, if the sample is split into two halves, than the distribution of the votes in the first sample can be used to calculate the chance that a randomly selected voter will vote for some party. Assuming that each and every respondent in the second subsample votes for the largest party in the first subsample (i.e. CDA) leads to the correct prediction of 33.3 percent of the actual votes in that second subsample. So, the power of our model is an increase of the number of correct predictions from 33.3 percent to 40.1 percent if we accept a very generous rule to count correct predictions. This result seems hardly worth the effort of the use of sophisticated statistical methods.

The results of these computations make clear that it is one thing to fit and estimate a model, but something quite different to predict actual outcomes. The elaborated model presented in Fig. 2 summarizes the tendencies in the covariance structures of the data in a satisfactory way and it can be used to discuss explanations of voting and party preferences. However, limited theoretical understanding of the decision-making process leading to the choice of some party, and rather crude and imperfect ways to measure central variables, prevent the precise prediction of the actual vote of a considerable part of the respondents in the second subsample.

This distinction between tendencies and precise outcomes is illustrated in 
Fig. 3. In this diagram the mean predicted party votes and the $95 \%$-confidence intervals are depicted for every party in the analysis. Fig. 3 shows that there exist remarkable inter-party differences in the dispersion of the predicted votes. The model seems to be much more accurate in predicting the vote for a small party like the PSP than for a party like the large CDA. This cannot be ascribed to a distinction between large or ideological diffuse parties on the one hand, and small or ideological puritan parties on the other, because small parties like SGP or CPN are less concentrated than the PSP, or even the PvdA. These differences in 'homogeneity' among voters for Dutch parties has been noted before (Van Deth 1984: 194-196). The number of cases in the present data set is too restricted to perform a more detailed analysis of this phenomenon.

\section{Conclusion}

We have tried to disentangle the constraints between so-called new and old political polarizations and their impacts on voting or party preference. It appeared that voting is most strongly related to the left-right placement of the respondents. However, that does not mean that the materialist/postmaterialist value orientation is irrelevant for the interpretation of voting behaviour. In fact, it turns out that left-right placement is directly and strongly dependent on this value orientation. This result has important consequences for the explanation of voting and party preferences, and the understanding of the actual meanings of the terms left and right.

The decline of social class-voting in advanced industrial societies has been illustrated by many authors. Using the familiar Alford Index of Class Voting, the decline of the tendency of manual workers to vote for left parties is clearly discernable in several countries in the past thirty years (Franklin 1985, Lipset 1981: 504, Inglehart 1987: 8). Since the number of people voting for these parties has not declined, the relevance of class or class conflict for voting behaviour must have been weakened considerably. In other words, the interpretation of left and right cannot be based on some implicit or vague reference to the traditional proletarian and bourgeois background of these terms captured under even more vague labels like 'social economic cleavages' or 'socio-economic conflict dimension'. The terms left and right - as Inglehart and Rabier (1986: 470) remark - are ' . . like a universal solvent, (that) tend to absorb whatever major conflicts are present in the political system'. The analyses presented here show that the dominant cleavage transformed into left and right terms, is the conflict over new non-economic issues. In the 1980s, the issues that determine the specific location on the left-right dimension to a high degree, are included in the materialist/postmaterialist value concept. ${ }^{23}$ 
The fact that electorates consequently stick to the use of the left-right dimension should not lead to the superficial conclusion that this dimension is the key factor for understanding voting behaviour or party preference. Behind this placement we find the materialist/postmaterialist value orientation as the present-day interpretation of the dominant political conflict in advanced industrial society. This explanation of the specific location on the left-right dimension transforms the trivial observation that left people prefer left parties into a theoretically relevant statement.

Finally, a more methodologically oriented remark should be made. Using sophisticated research techniques like LISREL leads to probabilistic conclusions based on the statistical tendencies in the covariance structures of the data set. Obviously, this type of information differs from the much more exact determination of factors required for the correct prediction of the score on some dependent variable. The analyses presented in this article illustrates the clear limitations of our theoretical understanding and measurement of the relevant determinants of actual voting behaviour. Since the final proof of understanding and explanation in empirical research is prediction, analysis of voting behaviour should not be limited to the search for structure in covariance matrices but, consequently, show its power by predicting the actual votes of respondents.

\section{Acknowledgments}

This article is a modified and enlarged version of a paper presented at the Annual Meetings of the Dutch Political Science Association, Amersfoort, The Netherlands, May 7-8, 1987.

\section{Notes}

1. 'By "left" we shall mean advocating social change in the direction of greater equality political, economic or social; by "right" we shall mean supporting a traditional, more or less hierarchical social order, and opposing change toward greater equality' (Lipset et al., 1954: 1135).

2. See Laponce (1981) for the interpretion of the terms left and right.

3. This theory has been discussed by Inglehart in many publications. See Inglehart (1977) or (1981). Recent findings are mentioned in Inglehart (1987) and Inglehart and Rabier (1986).

4. See Inglehart and Klingemann (1976) for the introduction of this problem and its place in the development of research on party preferences or voting.

5. See, for some information on the format of these instruments and their validity, Van Deth (1983).

6. In the Netherlands this method has been applied for about twenty years. See Van der Eijk and Niemöller (1983: 247-250) for an overview of the results.

7. Bijleveld (1984) characterized the four largest parties in the Netherlands on the basis of their 
party programme. With the help of content analysis he could pin down the extent to which the party was to be characterized as left-right and postmaterialistic. None of the differences between the characteristics of the programme of the four parties studied appeared to be significant.

8. C. van der Eijk, B. Niemöller, and A.Th.J. Eggen, Dutch Parliamentary Election Study 1981, Amsterdam: FSW-A. The data can be obtained from the Steinmetz Archives in Amsterdam (ICPSR study number 791211).

9. Eurobarometer 11 was left out of our analyses because it does not incorporate the standard instrument to measure the materialist/postmaterialist value orientation.

10. The phrase 'potential voters' is used instead of 'voters' because the question refers to prospective behaviour: 'If there were a general election tomorrow, which party would you support?'.

11. See Van Deth (1983: 423) for the details of this variant of the materialist/postmaterialist instrument.

12. Jöreskog developed a computer programme which makes it possible to combine linear regression analysis with factor analysis. The problem we have to solve here is a typical LISREL-problem, for we have a latent variable 'vote' which is measured by four indicators. We used the LISREL VI version of the programme (Jöreskog and Sörbom 1984).

13. Because the materialist/postmaterialist variable is of an ordinal character and the number of distinct scores is limited, we use polyserial correlations (Jöreskog and Sörbom 1984: IV.1-3). For this reason, and because the indicators of the vote are not normal distributed, we use the Unweighted Least Squares technique as the estimation method. Since no chi-square test nor standardization are applied, the parameters of the estimated models in this article must be handled with care. They function only to illustrate that the links between the variables are substantial. Just to have some indication of the meaning of the parameters in relation to the estimated variable, we have reported the variances of the most important estimated variables. As a measure of the goodness of fit of the model on the whole, we use the adjusted goodness of fit index as suggested by Jöreskog and Sörbom (1984: I.36-I.42). As an indicator of the degree of explanation of voting and the other endogenous variables, we use the squared multiple correlation. To judge the fit of the 'individual' parameters, the most important aspects of the residuals of the correlation matrix are reported. As a rule of thumb we use the old criterion of causal analysis that residuals of .10 or less are reasonable low.

14. By not allowing correlated residuals a confirmatory factor analysis does not lead to meaningful results because of a misspecification of the model on this data.

15. Actually we find a non-positive definite matrix of residuals in the measurement model (in LISREL-terms: the TE-matrix).

16. As far as the results of the testing of the complement model and the rejection model could be interpreted, these solutions resemble very much the two good fitting solutions, that is, the measurement models are the same but the explanatory models deviate.

17. See Inglehart (1977) and Van Deth (1984) for the interpretations of these relationships. There are two reasons for omitting the usual class variable. In the dataset the subjective status has been asked. In our view it is not clear what is measured by this question. It could be the education of the respondent, it could be the job (not the occupation) or it could be some reference to a solidarity grouping. Secondly, the left-right placement is classically connected with class in a more marxist sense. In that case, the accent has to lay on the relationship to the means of production. In this way 'class' is theoretical meaningful (see for example Wright and Martin 1987).

18. See the previous note for relevant references.

19. The theoretical and operational differences have been presented above. The main technical difference is that we use the unweighted least squares technique to estimate the parameters 
and so, that we do not present standardized solutions (see note 12). While Van der Eijk and Niemöller discriminate between continuous variables and discrete variables and compute different types of correlation coefficients $(1986,1987)$, they simply use the default routine of the LISREL-program for the estimation of their models. In this way, they seem to overlook the implications of measurement levels and distributions of the variables for selecting an estimation technique and the standardization of the parameters.

20. The exact formula is:

$$
\begin{aligned}
\text { Actual Vote }= & .271 *(\% \text { voteleft }-21.243) / 23.813 \\
& -.360^{*}(\% \text { voteright }-26.881) / 21.376 \\
& +.093 *(\% \text { votepostm }-17.362) / 12.586 \\
& -.103 *(\% \text { votemat }-32.000) / 8.879
\end{aligned}
$$

21. The following formula is used:

$$
\begin{aligned}
& \text { Predicted Vote }=-.142 *(.402 * \text { (postmat }-.000) / .896 \\
& \left.-.244^{*} \text { (age }-40.853\right) / 16.239 \\
& +.158 * \text { (education }-4.494) / 2.687 \\
& -.124 * \text { (income }-7.146 \text { )/2.994) } \\
& -1.112 *\left(.255^{*}(\text { leftright }-5.402) / 2.397\right. \\
& +.021 *(\text { education }-4.494) / 2.687 \\
& +.084 *(\operatorname{sex}-.000) / .799 \\
& -.779 *(.402 *(\text { postmat }-.000) / .896 \\
& -.244 *(\text { age }-40.853) / 16.239 \\
& +.158 * \text { (education }-4.494) / 2.687 \\
& -.124 * \text { (income - 7.146)/2.994) }
\end{aligned}
$$

The variables materialism/postmaterialism and left-right are part of the measurement model of the Beta-matrix. These parameters are, therefore, factor regression coefficients from the manifest to the latent variables. Materialism/postmaterialism and sex arc taken as ordinal, respectively nominal variables and so polychoric or polyserial correlation coefficients are used for these variables in the model. Normalized values are computed with the PRELIS-program (Jöreskog and Sörbom 1986).

22. Actually, we calculated the midpoints between the parties, estimated the party score, and counted the number of correct predictions.

23. See, for a more extensive analysis of the relevance of materialist/postmaterialist issues for the left-right placement of individuals, Inglehart and Rabier (1986: 471).

\section{References}

Bijleveld, R.J. (1984), Politieke Partijen als Rationele Aktoren; Een toetsing van de ekonomische theorie van de demokratie op basis van een materialisme-postmaterialisme spektrum en een linksrechts spektrum, Enschede, Unpublished manuscript, University of Twente.

Castles, Francis G., and Mair, Peter (1984), 'Left-Right Political Scales: Some 'Expert' Judgements', European Journal of Political Research 12, 73-88.

Franklin, M.N. (1985), The Decline of Class Voting in Britain; Changes in the Basis of Electoral Choice, 1964-1983. Oxford: Clarendon.

Inglehart, R. (1977), The Silent Revolution; Changing Values and Political Styles Among Western Publics. Princeton: Princeton University Press.

Inglehart, R. (1979), 'Political Action: The Inpact of Values, Cognitive Level and Social Background', pp. 343-80 in Barnes, S.H., Kaase, M. et al., Political Action; Mass Participation in Five Western Democracies. Beverly Hills: Sage. 
Inglehart, R. (1981), 'Postmaterialism in an Environment of Insecurity', American PoliticalScience Review 75, 880-900.

Inglehart, R. (1987), 'Value Change in Industrial Societies', American Political Science Review 81 , 1289-1303.

Inglehart, R. and Klingemann, H.-D. (1976), 'Party Identification, Ideological Preference and the Left-Right Dimension among Western Mass Publics', pp. 243-76 in Budge, I., Crewe, I., and Farlie, D., Party Identification and Beyond; Representations of Voting and Party Competition, London: Wiley.

Inglehart, R. and Rabier, J.-R. (1986) 'Political Realignment in Advanced Industrial Society: From Class-Based Politics to Quality-of-Life Politics, Government and Opposition 21, 456-479.

Jöreskog, K.G. and Sörbom, D. (1984), LISREL VI: Analysis of Linear Structural Relationships by the Method of Maximum Likelyhood, Mooresville: Scientific Software.

Jöreskog, K.G. and Sörbom, D. (1986), PRELIS: A Program for Multivariate Data Screening and Data Summarization, Mooresville: Scientific Software.

Kaase, M., and Klingemann, H.-D. (1982), 'Social Structure, Value Orientations, and the Party System: The Problem of Interest Accomodation in Western Democracies', European Journal of Political Research 10, 367-86.

Laponce, J.A. (1981), Left and Right. The Topography of Political Perceptions, Toronto etc.: University of Toronto Press.

Lipset, S.M. (1981), Political Man; The Social Basis of Politics, 2nd edition. Baltimore: John Hopkins University Press.

Lipset, S.M., Lazarsfeld, P.F., Barton, A.H., and Linz, J. (1954), 'The Psychology of Voting: An Analysis of Political Behavior', pp. 1124-76 in Lindzey, G. (ed.), The Handbook of Social Psychology, Volume II. Cambridge (Mass.): Addison-Wesley.

Prewitt, K. , and Nie, N. (1971), 'Review Article: Election Studies of the Survey Research Center', British Journal of Political Science 1, 479-502.

Van der Eijk, C., and Niemöller, B. (1983), Electoral Change in The Netherlands; Results and Methods of Measurement. Amsterdam: CT-Press.

Van der Eijk, C., and Niemöller, B. (1986), 'Links/rechts, postmaterialisme en stemgedrag', Mens en Maatschappij 61, 251-269.

Van der Eijk, C., and Niemöller, B. (1987), 'Electoral Alignments in the Netherlands', Electoral Studies 6, 17-30.

Van der Eijk, C., Niemöller, B., and Eggen, A.Th.J. (1981), Dutch Parliamentary Election Study 1981. Amsterdam: CT-Press.

Van Deth, J.W. (1983), 'Ranking the Ratings: The Case of Materialist and Postmaterialist Value Orientations', Political Methodology 9, 407-31.

Van Deth, J.W. (1984), Politieke waarden; een onderzoek naar politieke waarde-oriëntaties in Nederland in de periode 1970 tot en met 1982. Amsterdam: CT-Press.

Wright, E.O. and Martin, B. (1987), 'The Transformation of the American Class Structure 1960-1980', American Journal of Sociology 93, 1-29. 